\title{
O CORPO EM MOVIMENTO NO CARIMBÓ: uma contribuição no Desenvolvimento Sensório-Motor em Educação Física na Educação Infantil em Belém (PA)
}

THE BODY MOVEMENT AT CARIMBÓ DANCE: A contribution to the Sensory-Motor Development at Physical Education class in Early Childhood Education in Belém (PA)

EL CUERPO EN MOVIMIENTO EN CARIMBÓ: una contribución al Desarrollo Sensoriomotor en Educación Física en la Educación Infantil en Belém (PA)

\section{Ana D'Arc Martins de Azevedo}

Doutora em Educação (PUC/SP). Professora adjunta na Universidade do Estado do Pará (UEPA). azevedoanadarc@gmail.com.

0000-0003-4240-9579

\section{Camila Rodrigues Neiva}

Mestra pelo Programa de Pós-graduação em Comunicação, Linguagens e Cultura - PPGCLC (PPGCLC/UNAMA). camiius.rodrigues@hotmail.com.

0000-0003-3028-7201

\section{Edgar Monteiro Chagas Junior}

Doutor em Sociologia e Antropologia (PPGSA/UFPA). Professor e Pesquisador da Universidade da Amazônia - UNAMA, onde também coordena o Programa de PósGraduação em Comunicação, Linguagens e Cultura PPGCLC. edgar.chagas@unama.br.

0000-0003-2048-560X

Maria Betânia de Carvalho Fidalgo Arroyo

Doutora pelo Programa de Pós-Graduação em Administração (PPAD) da Universidade da Amazônia (UNAMA). Docente e pesquisadora no Programa de Pós-Graduação em Comunicação, Linguagens e Cultura (PPGCLC) da UNAMA. betania.fidalgo@unama.br.

\section{0-0002-7745-6394}

Correspondência: Universidade da Amazônia (UNAMA). Av. Alcindo Cacela, 287. 66060902 Belém/PA. Brasil. Fone: (91) 4009-3000.
Recebido em: 12.10.2020.

Aceito em: 20.11.2020

Publicado em: 01.01.2021.

RESUMO:
Este artigo destaca, o Carimbó como
símbolo da cultura tradicional e identidade
paraense, um instrumento para trabalhar a
teoria de Wallon sobre o desenvolvimento
sensório-motor. Teve como problemática,
conhecer a maneira que o Carimbó contribui
para o desenvolvimento sensório-motor em
alunos da Educação Infantil (maternal) nas
aulas de Educação Física. A pesquisa
qualitativa do tipo Estudo de Caso, utilizou
a observação participativa e a entrevista
aberta com uma professora e seis alunos.
Para a análise dos dados, foi utilizada a
Triangulação de Dados. Como resultados,
compreendemos que o Carimbó viabilizou o
desenvolvimento sensório-motor dos
alunos, pois foi possível observar o
desenvolvimento dos aspectos pesquisados.
PALAVRAS-CHAVES:
Desenvolvimento Carimbó;
Educação Física.

\section{Introdução}

O presente artigo é fruto de pesquisa realizada no ano de 2019 para o mestrado em Comunicação, Linguagens e Cultura da Universidade da Amazônia. Versa sobre o Carimbó, enquanto manifestação que envolve um complexo cultural, foi registrado em 2014 como patrimônio cultural imaterial do Brasil pelo Instituto do Patrimônio Histórico e Artístico Nacional - IPHAN. Trata-se de uma manifestação cultural que tem por centralidade a música e a dança de instrumento lúdico-pedagógico que pode contribuir no desenvolvimento sensório-motor na Educação Infantil, notadamente a partir das aulas de Educação Física e nas contribuições que as experiências da cultura do movimento corporal no contexto das formas de expressão amazônicas podem trazer no 
processo de formação do aluno, trabalhando, assim, com diferentes aspectos do desenvolvimento humano, como o afetivo, motor e cognitivo.

Pretende-se entao, apresentar a Educação Física voltada para a cultura corporal, partindo-se da dança, do jogo, da música do Carimbó para o desenvolvimento humano de criança nas séries iniciais. Compreendemos, apartir das referências aqui propostas, que as manifestações das cuturas locais podem ser um importante contribuidor no que tange ao domínio do corpo da criança na faixa etária de um a três anos, no sentido de aprimorar o controle necessário deste para o desenvolvimento de qualquer outra habilidade motora, bem como colabore para o desenvolvimento intelectual e a formação cidadã crítica em ralação ao seu lugar de origem.

De acordo com Caparroz (2007), nos anos 1980, no contexto de uma ampla movimentação social e política em prol da (re)democratização da sociedade brasileira, constituiu-se, também no âmbito da comunidade da Educação Física brasileira, um movimento, depois denominado de movimento renovador, que se caracterizou por uma forte crítica à função atribuída até então à Educação Física no currículo escolar. E é a partir daí que ocorre uma mudança radical na compreensão do conteúdo da disciplina.

A dança, por ser uma das mais essenciais formas de manifestação e expressão do movimento humano, é necessária para desenvolver o interesse dos alunos, envolvendoos cada vez mais nas culturas dos lugares. Considera-se, a partir disso, uma importante modalidade do processo ensino-aprendizagem no planejamento escolar, nas aulas de Educação Física, não como forma de mera reprodução de gestos, mas como meio de reflexão e estímulo sensório-motor do educando, buscando seu maior envolvimento, tornando-o mais crítico e participativo no contexto sociocultural que o cerca.

O Carimbó é um gênero de música e dança popular do norte do Brasil, cuja origem vem da fusão entre as culturas indígena, africana e ibérica, confundindo até os seus brincantes mais nativos quando questionados sobre sua procedência. Poucos são os registros históricos sobre a trajetória do Carimbó. Sabe-se que o nome se deu, de acordo com Salles e Salles (1969), através do instrumento de percussão indígena, o curimbó, feito com tronco de madeira escavado e encoberto com pele de animal. É mais comum na zona atântica do estado no Pará, não sendo, no entanto, ausente das demais regiões. Pratica-se, no interior do estado, principalmente nos meses de final e início de ano (novembro, desembro e janeiro), e na capital, é mais presente na quadra junina. De outro modo, em encontros, aniversários e festejos diversos que independem de um caledário fixo anual. É caracterizado por sua função comunicacional e históricamente vinculada aos eventos religiosos de santos parroeiros (ou não) da Igreja Católica nos municípios. 
O Carimbó é trabalhado na Educação Física Escolar de uma forma diferente, buscando vivências práticas baseadas nos valores éticos, morais, cívicos e sociais. Porém, é evidente a influência das ações competitivas e do processo de esportivização no ambiente escolar de desenvolvimento corporal da criança.

A Base Nacional Comum Curricular - BNCC, diz que nessa idade, de um a três anos, especificamente um ano e sete meses a três anos e onze meses, tem como objetivo de aprendizagem e desenvolvimento, deslocar seu corpo no espaço, orientando-se por noções, como frente, atrás, alto, embaixo, dentro, fora, etc., ao se envolver em brincadeiras e atividades de diferentes naturezas (BRASIL, 2016). Assim, na abordagem das experiências de aprendizagem na BNCC, as crianças bem pequenas, que são as consideradas de um a três anos, apropriam-se com interesse do espaço à sua volta, seja em sua sala ou no espaço externo, ao ar livre. Gostam de brincar uma ao lado das outras e se interessam pelos objetos, pessoas e ações ao seu redor.

De acordo com a Lei de Diretrizes e Bases (LDB) 9394/96, a Educação Infantil tem como objetivo proporcionar o desenvolvimento físico, emocional, cognitivo e social da criança. Além disso, Basei (2008) explica que é necessário que a escola, na Educação Infantil, permita que a criança tenha acesso a elementos da cultura universal e da natureza, podendo trocar experiências com outras crianças sendo o professor um mediador, tornando a escola um espaço socioeducativo. E na Educação Infantil, há necessidade de toda uma ambientação psicopedagógica própria, capaz de estimular o desenvolvimento sensório-motor da criança e as dobras culturais do seu processo de socialização.

Para Wallon (1975), o desenvolvimento da criança acontece naturalmente em meio ao seu ambiente sociocultural, ou seja, o processo de desenvolvimento é tratado de uma forma integrada, em que a realidade que vai sendo tecida não está somente no indivíduo, mas nas relações sociais e culturais que historicamente estão situadas na sociedade (em seus espaços e instituições).

O Carimbó, considerado um ritmo regional paraense, é costumeiramente abordado de alguma forma dentro do ambiente das escolas do estado, o que nos levou ao interesse de aprofundar os estudos em relação as diferentes ramificações do conhecimento que essa manifestação cultural proporciona em relação aos conteúdos da Educação Física nas séries iniciais. De maneira geral, compreende-se que ele pode auxiliar, de uma forma diferenciada, no desenvolvimento humano de cada aluno, trabalhando o ritmo, a flexibilidade, a musicalidade, a coordenação motora, o cognitivo e o social. É sabido que as crianças na Educação Infantil, que estão em uma faixa etária de um a três anos, necessitam de estímulos para o seu desenvolvimento. E é importante 
ressaltar que grande parte da literatura especializada assevera que o processo educativo sempre deverá promover atividades socializantes para desencadear a aprendizagem da criança.

Diante o exposto, partimos de uma questão de pesquisa: de que maneira o Carimbó contribui para o desenvolvimento sensório-motor em alunos da Educação Infantil (maternal) nas aulas de Educação Física em uma Escola em Belém do Pará?

A partir disso, partimos a investigar de maneira específica: a) as maneiras que 0 Carimbó, enquanto dança, contribui para o desenvolvimento da afetividade no aluno; $b$ ) as habilidades da dança do Carimbó que podem ser utilizadas para o desenvolvimento cognitivo; c) as formas que o Carimbó contribui para a coordenação motora.

\section{O Corpo em Movimento no Carimbó}

Entre as diversas danças folclóricas brasileiras, o Carimbó é característico da região norte do país, mais especificamente do Pará. Ele possui origens no sincretismo entre as culturas negra, indígena e portuguesa (GABBAY, 2010).

Símbolo da cultura tradicional e identidade paraense, o Carimbó não é voltado apenas para a dança e a música. Segundo Figueiredo e Bogéa (2015, p. 82), também "envolve modos de viver (manifestação cultural e movimento social) e modos de fazer (expressão artística e cadeia produtiva)". Ele tem destaque em todo o estado do Pará, com maior evidência em algumas regiões: Região do Salgado, Litoral Nordeste do Estado, Região Metropolitana de Belém, na Região do Guamá e na Ilha do Marajó.

O Carimbó é encontrado em quase todas as regiões do Pará, e há mais de dois séculos mantém sua tradição juntamente ao processo de reinvenção. Ele traz, como características, os instrumentos, a dança e a música, resultantes de influências culturais indígenas, negra e ibérica. Sua organização e reprodução social dos "carimbozeiros", em referência ao cotidiano de trabalho e de celebrações religiosas, formam a estrutura marcante de sua formação. Ela incide nas práticas de lazer, religiosidade, manifestação artística, festas públicas e familiares (FIGUEIREDO; BOGÉA, 2015).

O Carimbó, enquanto forma de expressão, manifesta-se durante todo o ano, e sua história remonta ao século XVII, na região da Amazônia, que corresponde ao atual Pará. De acordo com os registros existentes, os batuques que deram origem, entre outros ritmos, ao Carimbó, foram trazidos ao Brasil por negros escravos africanos e incorporou influências indígenas e ibéricas, dando origem a uma manifestação singular, representada por grupos que se espalham por vários municípios (FIGUEIREDO; BOGÉA, 2015). Para Souza (2011), foi com a chegada dos negros na região que o Carimbó ganhou novas características; tornou-se um ritmo mais acelerado, com uma dança mais agitada 
e cheia de requebrados. Assim, ficou conhecido como "limpa bancos", pois ninguém conseguia ficar parado com esse ritmo.

O nome Carimbó teve origem do instrumento de percussão indígena chamado "Curimbó", que é confeccionado de tronco de madeira e pele de animal. Cascudo (1972) interpretou que "curi" teria o significado de madeira e "imbo" de ôca, dando característica a esse instrumento que é utilizado para propagar o som, trazendo o ritmo ao Carimbó. Curimbó, segundo Gabbay (2010, p. 2), é "o principal artefato para a realização dos encontros em terreiros, [...] caracteriza por sua função comunicacional e vinculativa em torno dos rituais religiosos, festas populares e reuniões sociais".

Cada Região apresenta sua particularidade na dança, como, por exemplo, em Soure, munícipio da Ilha do Marajó, e em Marapanim e Maracanã, municípios litorâneos da região do Salgado Paraense, em que Figueiredo e Bogéa (2015, p. 83) descrevem, respectivamente, o "chamado de Carimbó Pastoril" e o "Carimbó Praieiro".

De acordo com Neves (2013), a coreografia geralmente é apresentada em pares e em círculos. Inicia com uma fila de homens e outra de mulheres; quando a música começa, os homens dançam se dirigindo às mulheres e batendo palmas, indicando um convite para a dança, elas aceitam, iniciando a apresentação; em seguida, os casais giram continuamente em torno de si mesmos e no grande círculo.

Com relação às vestimentas, os dançarinos de Carimbó se apresentam descalços. As mulheres usam saias longas, rodadas e estampadas, com blusas normalmente de cores claras e lisas, mostrando ombros e barriga, além usarem pulseiras e colares feitos de sementes da região paraense e flores nos cabelos. Os homens dançam com calças geralmente brancas com as bainhas enroladas, herança da cultura negra; as blusas possuem cores fortes, com as pontas amarradas na altura do umbigo, lembrando a vestimenta que a população ribeirinha utilizava até meados do século XX. Na cabeça, o tradicional chapéu de palha, e um lenço enrolado no pescoço (NEVES, 2013).

O acompanhamento da dança é feito por dois tambores, ganzá, reco-reco, banjo, flauta, maracás, afoxé e pandeiros. Porém, existe também um desdobramento mais moderno do Carimbó, que surgiu depois do sucesso do cantor Pinduca, nome artístico de Aurino Quirino Gonçalves. Ele foi responsável pelo lançamento nacional do Carimbó, com a inclusão de instrumentos elétricos e de sopro no Carimbó tradicional, com destaque especial para o baixo elétrico que, nos arranjos, faz uma linha bastante original e característica.

Foi no ano de 1970 que a música do Carimbó passou a interessar intelectuais e folcloristas. Porém, ainda não era uma música do consumo urbano, ou seja, das classes médias e da indústria cultural; era mais consumida pelos setores populares, interioranos 
e suburbanos. Salles e Salles (1969, p. 259) ressalta que era "o divertimento que mais anima as populações dessa região", pois estava presente em todas as festas, sendo elas particulares ou em festejos regionais.

O cantor paraense, Pinduca, é um dos principais representantes da música do Carimbó, bem como o Mestre Verequete, que foi o primeiro a gravar o Carimbó e colocar para tocar nos salões. Em 1971, ele criou o grupo "O Uirapuru do Amazonas", que se apresentava em diversos locais, sendo o principal em Icoaraci, distrito da cidade (COSTA, 2011, p. 10).

E a partir desse momento, o Carimbó passou a ser conhecido e visto por todo o mundo. Saindo um pouco de sua visão regional para uma visão global. E o que essa globalização trouxe ao Carimbó? Hoje, ele é visto por muitos como entretenimento, cuja conotação essencial está na formação de identidade e memória de uma nação, como também representação de um povo, trazendo nas danças (coreografias) e nas vestimentas de seus participantes as características do paraense.

Foi a partir da década de 1970 que o Carimbó chegou à cidade de Belém, sendo dançado nos bares, em shows e casas de festas sociais. Diversos grupos e gravações de vários LPs colocaram o Carimbó na televisão e nas rádios. Mas foi em 1990 que o Carimbó chegou à mídia do mundo inteiro, através dos diversos conjuntos musicais que se formaram e, assim, se tornou tendência nos ritmos musicais brasileiros. "Cantores da terra" foi uma gravação em que cantores consagrados regionais (Pinduca, Nilson Chaves e Fafá de Belém) apareceram na mídia regional, divulgando o Carimbó como produto da indústria cultural, dando cada vez mais visibilidade e credibilidade ao ritmo.

Em 11 de setembro de 2014, o Carimbó foi registrado, por unanimidade, pelo Conselho Consultivo do Patrimônio Cultural, como Patrimônio Imaterial do Brasil. Um grupo de artistas, pesquisadores, produtores culturais e a comunidade carimbozeira do Pará organizaram a "Campanha do Carimbó", que tinha como objetivo, de acordo com Figueiredo e Bogéa (2015, p. 90), "consolidar a valorização do Carimbó, principalmente através das ações pós-registro, que perpetuem, depois do registro do IPHAN em 2014, a constante legitimação dessa importante expressão cultural".

Então, o "Carimbó tradicional" sofre diversas alterações e adaptações; a mais perceptível foi do curimbó, que não está mais solitário, pois diversos instrumentos ingressaram para compor o ritmo, passando a ser um "Carimbó moderno". Gabbay (2010) diz que, mesmo com todo esse crescimento, ele ainda consegue manter-se fiel a suas raízes, e o que realmente traz a mudança é a força política, a qual acaba apontando sempre a questão do tradicional e do moderno. 
E ser moderno é se atualizar constantemente, sempre tentando compor o chamado, por Gabbay (2010), "caldeirão cultural contemporâneo". Não cantar apenas Carimbó, e sim misturar esse ritmo com os demais gêneros que são tendência no mundo, tornando-o sempre um componente híbrido, podendo ser inserido nos festivais, festas e apresentações de artistas.

Uma alteração significante foi no ritmo do Carimbó: passou a ser mais rápido e deixou de ser apenas uma dança coreográfica. No início, os dançarinos demonstram os passos básicos e em seguida realizam a introdução dos turistas na dança, dando a oportunidade da vivência. $E$, com isso, o turismo transformou o Carimbó em um trabalho, como ressalta Figueiredo e Bogéa (2015, p. 88): "assim, o turismo transforma o brincante em componente de grupo parafolclórico, isto é, em trabalhador, o que é um primeiro movimento redutor".

Esse movimento redutor se dá pelo fato do Carimbó, agora interpretado como dança típica do paraense, deixar as festas da comunidade e passar facilmente a ser encontrado nos salões dos hotéis, pontos turísticos e festivais programados pelo governo. O turismo modifica o brincante, que antes tinha o ritmo como lazer, e agora se transforma em trabalhador, dançando para ganhar dinheiro. Diante disso, Figueiredo e Bogéa (2015, p. 85) afirmam que "o Turismo é o principal nicho de atuação dos grupos parafolclóricos, além das apresentações em eventos dos órgãos oficiais de cultura e turismo, como as festas juninas e o Círio de Nossa Senhora de Nazaré".

Segundo Figueiredo e Bogéa (2015, p. 88), "o Carimbó migra, então, para os guetos turísticos, que são os espaços e equipamentos criados especificamente para o turismo". E essa mudança é relatada pelos moradores antigos, onde o Carimbó deixa as casas e as festas privadas (casamentos, batizados, aniversários) para se apresentar nos grupos parafolclóricos, em eventos culturais organizados pela prefeitura.

De acordo com Giffoni (1973), a palavra folclore é derivada da fusão da palavra "folc" que, nos dialetos anglo-saxônicos, quer dizer povo, e "lore", no sentido do saber, isto é, no sentido tradicional do saber do povo.

O trabalho das danças populares e folclóricas no currículo de Educação Física não poderá basear-se somente no reconhecimento das diferenças ou tratá-las como produtos exótico oriundos de grupos desqualificados. O que se está sugerindo é que cada dança tenha suas marcas culturais (gestos, ritmos, adereções, representantes, coreografías, etc.) transformadas em objeto de leitura crítica, vivência e reflexão.

\section{O Desenvolvimento Sensório-Motor na Criança}


Para Wallon (1975), o meio primordial para a criança é o meio social, sem o qual as transformações humanas não são possíveis. O meio social constitui-se na primeira realidade da criança e no início de toda a educação consciente que o adulto pode oferecer. Essa visão não implica considerar o desenvolvimento como diretamente determinado pelo adulto, mas compreender que a criança se desenvolve na relação de sua plasticidade, entre seu ser biológico e o meio social. Nesse sentido, a educação é uma necessidade da criança, tanto quanto a sua alimentação.

De acordo com Wallon (1975), o homem, como ser, é resultado da integração de quatro conjuntos funcionais: afetividade, ato motor, cognição (inteligência) e pessoa. No início da vida, esses conjuntos encontram-se indiferenciados; porém, com o desenvolvimento, vão assumindo funções e atividades específicas. A afetividade caracteriza-se pelas disposições emocionais e sentimentos; o ato motor pelo movimento corporal geral; a cognição pela estruturação do pensamento; e a pessoa, pelo resultado da integração dos três conjuntos funcionais, constituindo a unidade do ser.

No estágio sensório-motor, a criança realiza um extenso e diferenciado acordo entre as percepções e os movimentos. Esta relação, em sua forma mais simples, é o ato reflexo, ou seja, uma determinada excitação corresponde um determinado movimento. O conjunto afetivo oferece as funções responsáveis pelas emoções e pelos sentimentos. O conjunto motor oferece a possibilidade de deslocamento do corpo no tempo e no espaço. E o conjunto cognitivo oferece um conjunto de funções que permite a aquisição e a manutenção do conhecimento por meio de imagens, noções, ideias e representações. É ele que permite ainda registrar e rever o passado, fixar e analisar o presente e projetar futuros possíveis e imaginários.

\section{Educação Física e a Cultura Corporal do Movimento}

Na década de 1980, a Educação Física era vista apenas como uma atividade física, em que os alunos deveriam ser submetidos a atividades cujo principal objetivo era melhorar a aptidão física, além de influir no comportamento, moldando o caráter.

De acordo com Souza Junior, (2011), a aptidão física foi, por muito tempo, o critério fundamental não só para a seleção dos conteúdos e para sua organização sequencial, como também para a realização da avaliação. $O$ documento legal que expressou isso claramente foi o Decreto Lei $n^{\circ}$ 69.450, de 1971 - editado, portanto, durante a Ditadura Militar, pós-1964.

É importante ressaltar que nesse período o conteúdo de Educação Física na escola era baseado fundamentalmente no exercício corporal através de exercícios analíticos, corridas, saltos, etc. Ou seja, assumindo, através destes conteúdos e das formas, as 
características trabalhadas em uma instituição militar. E a relação professor e aluno ocorria de maneira direta, em que o professor apresentava os exercícios e o aluno deveria executar, sem qualquer tipo de troca de experiências.

Segundo Souza Junior (2011), nas décadas de 1970 a 1990, a Educação Física tornou hegemônica a atividade física voltada para o esporte. Isso aconteceu pelo fato de que, nas políticas públicas para o setor da Educação Física e do Esporte, a Educação Física Escolar foi concebida e integrada ao sistema esportivo brasileiro, tendo como uma de suas mais importantes funções promover a iniciação esportiva, no sentido de identificar talentos.

De acordo com Caparroz (2007), nos anos 1980, no contexto de uma ampla movimentação social e política em prol da democratização da sociedade brasileira, constituiu-se, também no âmbito da comunidade da Educação Física brasileira, um movimento, denominado de movimento renovador, que se caracterizou por promover uma forte crítica à função atribuída, até então, à Educação Física no currículo escolar. Esse movimento desatrelava a ideia de uma Educação Física voltada para o esporte, valorizando o processo de aprendizagem e não mais a execução de um gesto técnico isolado. E é a partir daí que ocorre uma mudança radical na compreensão do conteúdo da disciplina.

Atualmente, o objetivo da Educação Física passa a ser o plano geral da Educação Integral. O conteúdo se torna instrumento para promover as relações interpessoais e facilitar o desenvolvimento da natureza da criança, utilizando formas variadas de movimentos corporais, diferenciando-as das atividades estereotipadas do esporte de alto nível. Adaptar, modificar, criar formas de movimento são, agora, as palavras de ordem.

$\mathrm{Na}$ Educação Infantil, o conhecimento a respeito da cultura corporal é desenvolvido, prioritariamente, de forma vivencial. Nesse momento, as aulas de Educação Física devem propiciar uma ampla gama de oportunidades motoras, a fim de que $o$ aluno explore sua capacidade de movimentação, descubra novas expressões corporais, domine seu corpo em várias situações, experimente ações motoras com novos implementos e com ritmos variados. A função do professor nesse ciclo será de levar o aluno, ao realizar as ações motoras, a compreender seu significado e as suas formas de execução.

A escola infantil é, portanto, conforme nossa compreensão, um lugar de descobertas e de ampliação das experiências individuais, culturais, sociais e educativas, através da inserção da criança em ambientes distintos do familiar (BASEl, 2008. p. 01). E essas práticas pedagógicas necessitam dialogar com os elementos culturais, lúdicos e 
sociais que fazem parte do cotidiano das crianças e de suas famílias, consolidando, assim, ações socialmente referenciadas. Logo, a Educação Física poderá contribuir para o programa de efetivação da Educação Infantil, trabalhando com o processo de desenvolvimento da criança e com a formação do sujeito.

\section{Método}

A pesquisa apresentada neste artigo, é uma pesquisa de campo do tipo Estudo de Caso de abordagem qualitativa e de enfoque fenomenológico. Ela foi submetida ao comitê de ética, obedecendo a Resolução 196/96-CNS, que trata dos instrumentos de pesquisa, juntamente com o Termo de Livre Consentimento e Esclarecido - TCLE e o Termo de Assentimento Livre e Esclarecido - TALE e o Termo de Autorização do Uso de Imagem, Depoimento e/ou Gravação.

A pesquisa foi realizada em uma escola em Belém (PA) no ano de 2019, cujos participantes foram: uma professora; seis alunos da turma do Maternal, sendo dois do sexo feminino e quantro do sexo masculino, todos com idade de tres anos. A coleta dos dados foi realizada pela manhã, uma vez na semana, com duração de 45 minutos, no decorrer de 2 meses. O diário de campo contribuiu para o registro das anotações, para depois obter uma melhor compreensão do comportamento e do desenvolvimento dos alunos durante as atividades direcionadas. Como a pesquisa ocorreu durante as aulas de Educação Física, então foi utilizada a quadra da escola para os encontros com os alunos. Foram realizadas doze atividades, cada atividade recebeu um nome e foram distribuidas três por encontro. Sendo que, após quatro encontros as atividade, se repetiam. Em todas as atividades utilizamos a caixa de som e um computador para transmitir as músicas do Carimbó.

E para efetuar a análise dos dados pela Triangulação dos Dados, foram utilizados os indicadores de análise que estavam em constante diálogo com os autores afins, juntamente com o objeto de estudo da pesquisa.

\section{Resultados e Discussões}

Na primeira entrevista com a professora, procuramos entender de que forma, ela realizava suas aulas com os alunos e como eles estavam na questão afetiva, cognitiva e motora. Conhecendo, assim, um pouco mais dos alunos que participariam da pesquisa.

De acordo com a professora, a afetividade, cognição e habilidades motoras são sempre trabalhadas em suas aulas. São aspectos que os alunos precisam desenvolver durante o ano. Ela diz: "qualquer atividade que é feita em sala com eles tem pelo menos um desses aspectos sendo trabalhados" (entrevista realizada em 17 de março de 2019). 
E quando perguntamos à professora sobre o Carimbó, ela nos confirmou que ele não está dentro do conteúdo relacionado ao maternal, que é a sua turma. Porém, ela trabalha o assunto no mês do Folclore e na Festa Junina: "Nesses momentos focamos mais no regional. Então, mostramos os trajes da dança, e fazemos alguns passos e sempre trabalhamos a letra da música com a interpretação" (entrevista realizada em 17 de março de 2019).

A professora diz que em relação aos aspectos afetivos, ela desenvolve um trabalho através do diálogo, chamado de "roda de conversa". Nessa roda de conversa, os alunos sentam no chão, juntamente com ela, em forma de um círculo; nesse momento, são observados os comportamentos destes e, caso tenha algum conflito, ele é solucionado no grupo. A professora esclarece: "Porque nessa idade, eles têm muita dificuldade de compartilhar objetos, compartilhar materiais, então enfatizamos o respeito ao próximo; ao espaço; às diferenças e, principalmente, à atitude de pedir desculpas" (entrevista realizada em 17 de março de 2019). Nessa idade, algumas crianças ainda resistem em pedir desculpas, por isso ela enfatiza muito essa ação nesse processo.

Para Wallon (1995), a emoção é a exteriorização da afetividade, ou seja, sua expressão corporal. É quando a criança estabelece os primeiros laços com o mundo humano através do mundo físico. E o sentimento corresponde à expressão representacional da afetividade, não implicando em relações instantâneas e diretas como na emoção.

Outra atividade realizada, que trabalhamos com o aspecto afetivo, foi "Segue o mestre", desta vez já sem o auxílio do bambolê, apenas da caixa de som. Durante a música, direcionamos um passo do Carimbó e eles imitaram; depois, passamos a vez para uma das crianças e ela fez outro passo de Carimbó; e então, repetimos o movimento até todas terem sido o "mestre". Essa foi uma atividade que envolveu a memória dos passos já trabalhados na aula passada e da percepção do seu espaço durante a dança. Quanto à dança do Carimbó, Salles e Salles (1969, p. 261) a descreve como "uma dança que contém homens e mulheres em pares, os quais dançam soltos e, durante a apresentação, vão se formando "configurações coreográficas solistas".

De acordo com a professora "eles gostaram muito do contato com o Carimbó" (entrevista realizada em 17 de março de 2019), e essa aceitação facilitou o trabalho desenvolvido com eles e a relação deles como amigos, os aproximando cada vez mais. Durante essa atividade, relatamos apenas uma impaciência por parte de uma das meninas, que, por não aceitar que os colegas repetissem os passos que ela desenvolveu, chorava. E os dois amigos que repetiam, provocavam a amiga para que chorasse mais. Diante disso, foi necessário conversar com eles para melhorar o andamento da atividade 
e diminuir os conflitos. Por conta da conversa, a atividade passou um pouco do tempo determinado. Mas, ao final, alcançamos o objetivo: realizar passos diferentes do Carimbó por cada aluno .

A atividade do aspecto afetivo que chamamos de "Carimbó", foi usado o Curimbó para contar a sua história e aproximar as crianças desse elemento importante para a construção do nome e do ritmo do Carimbó. E trabalhamos, com o auxílio desse elemento, a dança e o ritmo. Eles ficaram empolgados ao ver o instrumento, mas, por ser bem pesado, não puderam movimentar e tirá-lo do chão. Todos tiveram a oportunidade de sentar em cima e "tocar" uma música no Curimbó. Esse contato com o instrumento chamou bastante a atenção deles, proporcionando um comportamento impecável, no sentido de que não houve qualquer tipo de comportamento inadequado durante a realização da atividade.

Por meio da atividade desenvolvida, "Menina o que fazer com essa saia rodada", inspirada em uma música da cantora paraense, Lia Sophia, utilizamos uma saia de Carimbó, e colocamos os alunos ao redor dela, cada um segurando uma parte. Ao som da música, jogamos uma bola de plástico e, juntos, eles movimentaram a saia até que a bola caísse na sua abertura, desenvolvendo, assim, um trabalho em equipe. Eles executavam a dinâmica ao som da música tema. A atividade foi muito divertida, e as crianças se encantaram ao ver a saia de Carimbó. Antes de colocarmos a bola no meio da saia para realizar o trabalho, deixamos que eles manuseassem um pouco a peça para diminuir a ansiedade. Eles ficaram levantando a saia por uns 5 minutos, em seguida, direcionamos a atividade.

Quando a bola foi colocada ao meio pela primeira vez, eles balançaram muito forte a saia e a bola saiu da peça, e uma das crianças teve que buscá-la. Nem na primeira, segunda, terceira e quarta tentativa a bola passou pelo buraco. Dois dos meninos estavam apenas balançando por balançar a saia, já as duas meninas e dois meninos rapidamente compreenderam que deveriam balançar devagar e juntos, para que a bola alcançasse o buraco. Com isso, as crianças que estavam tentando realizar a atividade passaram a se estressar e a brigar com os dois meninos que não estavam colaborando da melhor forma. E um dos meninos que já tinha compreendido a atividade começou a chorar, tanto pela atividade não estar dando certo quanto pelos amigos que não estavam entendendo. Ele até se retirou da atividade por um momento.

Num outro encontro com as crianças, fizemos a atividade chamada de "Segue o Mestre", ao utilizarmos os maracás de garrafas que as crianças construíram na atividade do aspecto motor. $E$, desta vez, criamos os movimentos com os nossos instrumentos, mudando um pouco o que realizado no mês anterior. Buscamos, nesse momento, um 
pouco da criatividade de cada aluno. E foi relevante ver as crianças executando movimentos diferentes e criativos com os instrumentos, fazendo com que os demais colegas repetissem. Percebemos que, ao introduzirmos os maracás nessa atividade, os conflitos diminuiram e o auxílio de um colega com o outro foi maior, pois quando era vez de um realizar o movimento, os colegas ficavam mostrando os movimentos que poderiam ser feitos, orientando, assim, os amigos. Até a aluna que estava bem chorosa no encontro anterior, conseguiu alcançar seus objetivos de uma forma bem agradável.

Em outra atividade, quando levamos novamente o Curimbó, os alunos já estavam familiarizados com o instrumento, tanto que já chegaram sentando e querendo batucar. E precisamos, nesse momento, retirar todos de cima para poder começar a atividade. Um de cada vez teve a oportunidade de batucar, e, juntos, cantamos uma música de Carimbó. Eles só lembravam da música da cantora paraense, Dona Onete, "No meio do pitiú", que foi trabalhada na atividade do aspecto cognitivo, "Memorizando", em que desenvolvemos uma pequena coreografia.

Ao desenvolver a atividade "Menina o que fazer com essa saia rodada", tivemos uma certa facilidade devido os alunos já a conhecerem. Conseguimos desenvolver nos dez minutos que planejamos para ela; as crianças dançavam ao som da música que era tocada, mesmo com uma tarefa para ser desenvolvida, aproveitando completamente a atividade, buscando encontrar a contribuição da dança para o desenvolvimento da afetividade e despertar nos alunos, o sentimento de respeito ao próximo, o controle de suas emoções diante de conflitos e a expressão de seus sentimentos com o auxilio da música.

De acordo com Wallon (1995), o desenvolvimento da afetividade está relacionado aos comportamentos afetados da criança pelo mundo externo/interno. Assim, a professora desenvolve esse aspecto, através da fala durante a "roda de conversa", em que ela coloca os conflitos para os alunos e diáloga com eles, fazendo com que reconheçam atos e atitudes equivocadas e evitem repeti-las.

Perguntamos à professora se foi percebido algum avanço no desenvolvimento dos aspectos afetivos desses alunos, e ela relatou: "percebi uma maior interação e cumplicidade entre eles" (entrevista realizada em 17 de março de 2019). Além disso, durante a pesquisa, as crianças ficaram mais falantes e mais observadoras durante a fala da professora, apresentando um tempo de concentração maior.

Dessa forma, segundo Wallon (1995), o conjunto cognitivo oferece um conjunto de funções que permite a aquisição e a manutenção do conhecimento por meio de imagens, noções, ideias e representações. É ele que permite ainda registrar e rever o passado, fixar e analisar o presente e projetar futuros possíveis e imaginários. 
Em continuidade com as atividades de pesquisa, realizamos a chamada "Toca do coelho", que consiste em espalhar os bambolês pelo espaço da quadra, cada criança com o seu. Ao som da música de Carimbó, as crianças devem dançar no espaço do bambolê, e assim que a música é interrompida, elas devem correr para outro bambolê. Com o tempo, os bambolês vão sendo retirados e a criança que estiver sem bambolê vai saindo da atividade. Trabalhando, nessa atividade, a questão de perder, ganhar e respeitar o colega, sem precisar empurrar para entrar no bambolê.

Conseguimos uma boa compreensão das crianças quando a atividade foi explicada. Surgiu o sentimento de ansiosidade por parte das meninas para trocar de bambolê, tanto que, muitas vezes, acabavam não dançando dentro do bambolê. Os meninos tiveram uma participação muito significativa nesta atividade, porém dois perderam bastante tempo na hora de trocar de lugar, por não estarem atentos na atividade. Um dos meninos rapidamente compreendeu a atividade, tanto que ele venceu as três vezes que ela foi executada.

Dando prosseguimento, outra atividade do aspecto cognitivo foi realizada, chamada, "Memorizando". Escolhemos uma música de Carimbó e, a partir dela, desenvolvemos uma coreografia, ou seja, passos combinados e ordenados para serem feitos durante a música. Com essa atividade, estimulamos a memória dos alunos. Segundo Giffoni (1973), existem diferentes e importantes valores para o trabalho com as danças folclóricas na escola, um deles é o valor mental, que visa desenvolver as funções da atenção, imaginação, memória e raciocínio.

A seguinte atividade que chamamos de "Mestres do Carimbó", apresentamos às crianças alguns elementos e músicas características desses cantores e compositores do nosso Carimbó, como músicas tradicionais desses músicos, elementos de sua vestimenta e estilo de suas danças, com o objetivo de obter maior interatividade com a cultura do Carimbó. Assim, utilizaram o instrumento para tocar, do jeitinho deles, e cantamos algumas músicas de alguns Mestres, para que eles já fossem conhecendo. Ao mostrarmos algumas fotos e vídeos desses Mestres, apresentamos à turma algumas vestimentas características destes músicos.

Segundo Wallon (2007), o desenvolvimento da pessoa como um ser completo não ocorre de forma linear e contínua, mas apresenta movimentos que implicam integração, conflitos e alternâncias na predominância dos conjuntos funcionais. No que diz respeito à afetividade e cognição, esses conjuntos revezam-se, em termos de prevalência, ao longo dos estágios de desenvolvimento.

A atividade, "Ah! Como é bom pescar", que faz referência à letra de uma das músicas do Mestre Lucindo, trabalhamos com uma rede de Futsal, que normalmente é 
colocada nas traves do gol, para simular uma grande rede de pesca. Lançamos essa rede na quadra, espalhamos quarenta e quatro peixinhos coloridos de plástico e, ao som da música, os alunos deveriam pegar os peixinhos que estavam na rede. Em seguida, deveriam levá-los para fora da rede e contar quantos foram pescados por eles e quais suas cores, desenvolvendo, assim, habilidades de contar e reconhecer as cores. Jogamos a rede no chão e colocamos os peixinhos espalhados. Todos realizaram a atividade juntos. Ao sinal da música, eles correram, ficaram em cima da rede pegando os peixinhos. Uma das meninas prendeu bastante o pé na rede e caiu várias vezes, deixando seus peixinhos caírem das mãos, proporcionando a captura destes por outras crianças. Depois que não tinha mais peixinhos na rede, todos voltaram aos seus lugares para conferir quantos tinham pegado e quais as cores. Quatro crianças pegaram quase a mesma quantidade de peixinhos, mas outras duas crianças pegaram uma quantidade muito menor. As duas crianças que pegaram poucos peixes foram: a menina que se enrolava na rede e caía e um menino que não conseguia colocar os peixinhos nos braços, pois os brinquedos escorregavam.

A atividade "Mestres do Carimbó" realizada pela segunda vez, mais uma vez utilizamos o Curimbó como suporte para lembrar as músicas cantadas pelos Mestres que conhecemos no encontro anterior. E quando um dos meninos estava sentado e tocando no Curimbó, outro menino foi lá e o empurrou de cima do instrumento, dizendo que era a vez dele e que o amigo já tinha tocado muito. Na hora a atividade precisou de uma pausa, para conversarmos sobre essa atitude e para socorrer a criança que caiu.

Para Wallon (1975), a educação precisa respeitar a totalidade da personalidade e integridade dos processos de evolução e aprendizagem da criança, considerando o aluno inserido no contexto vivido, direcionado para o desenvolvimento da autonomia de sua autonomia.

A cognição é vista como parte da pessoa completa, que só pode ser compreendida integrada a ela, cujo desenvolvimento se dá a partir das condições orgânicas da espécie, e é resultante da integração entre seu organismo e o meio, predominantemente o social. Assim, o desenvolvimento é condicionado tanto pela maturação orgânica, como pelo exercício funcional, propiciado pelo meio (WALLON, 1995).

Conversamos com a professora sobre o comportamento das crianças ao longo da pesquisa, ela disse que "eles sempre voltavam mais eufóricos, mais falantes" (entrevista realizada em 17 de março de 2019). E passaram a se expressar mais durante as demais atividades. A relação de respeito entre os colegas aumentou e, com relação ao desenvolvimento dos aspectos afetivos, cognitivos e motores, ela relatou como "amadurecimento" por parte das crianças. Nesse aspecto, para Wallon (1975), o professor 
se torna um elemento fundamental do processo educacional sistematizado, pois é o organizador do ensino centrado no desenvolvimento integral das possibilidades e aptidões do aluno.

Para Wallon (1995), os aspectos motores, como correr, saltar, pular, lançar, agarrar e bater são movimentos fundamentais que devem ser aprendidos antes de serem combinados com outras competências, para se tornarem competências motoras especializadas. E os aspectos motores, a professora trabalha dentro de sala e ao ar livre: "Desde rasgar o papel, fazer bolinha de papel, fazer colagem, a própria pintura e desenho deles, caminhada em linha reta e linha curva" (entrevista realizada em 17 de março de 2019). Ela utiliza infinitas brincadeiras e atividades para desenvolver essa coordenação motora na criança.

Na atividade "Troca Troca", que nos ajuda a desenvolver o aspecto de corrida, lateralidade e salto. Colocamos de um lado da quadra as crianças dentro do espaço do bambolê e uma ao lado da outra; ao som da música, elas devem realizar tarefas, como dançar, saltar, girar, etc., dentro do seu bambolê; e assim que a música for interrompida, elas devem correr até o outro bambolê disposto do outro lado da quadra. Nessa atividade, também podemos trabalhar o tempo de reação dos alunos assim que a música parar.

Como segunda atividade do aspecto motor, realizamos a atividade denominada "Construindo o instrumento"; com o auxílio de garrafas pet pequenas e pedrinhas, construímos os maracás recicláveis. Aí, foi trabalhado o aspector motor no ato de colocar cada pedrinha no buraco da garrafinha e no movimento de sacudir o instrumento criado, auxiliando a coordenação motora fina da crianças. A escola infantil é, portanto, conforme nossa compreensão, um lugar de descobertas e de ampliação das experiências individuais, culturais, sociais e educativas, através da inserção da criança em ambientes distintos do familiar (BASEI, 2008).

Para realizar a atividade, saímos da quadra e nos dirigimos para o parquinho da escola, onde tinha pedrinhas para colocarmos nas garrafas pet durante a construção dos nossos maracás. As meninas colocaram as pedrinhas com facilidade na garrafinha, pois elas sempre procuravam as pedras menores. Já os meninos não observavam muito a questão do tamanho das pedras; se a pedra fosse muito grande, eles imprimiam mais força na hora de passá-la pelo buraco da garrafa.

No encontro de número três, fizemos a atividade do "Quebra-cabeça", na qual as crianças vivenciam a construção das vestimentas utilizadas no Carimbó. Um menino e uma menina feitos de papelão são colocados em uma extremidade da quadra e as pecinhas das roupas são colocadas do outro lado; ao som do apito o aluno deve procurar 
no pote as roupas de Carimbó e ir até o bonequinho de papelão encaixar a roupinha certa, até que os dois bonecos fiquem arrumados com as roupas de Carimbó; auxiliando, assim, a criança a reconhecer um dos elementos da cultura do Carimbó e, ao mesmo tempo, trabalhando a corrida e encaixe das peças nos bonecos.

Durante a atividade, nenhuma das crianças acertou a combinação completa das roupas de Carimbó dos bonequinhos. Porém, o que mais chamou atenção foi uma das meninas que, apesar de todos os dias vivenciando o Carimbó nas atividades, não encaixou nenhuma das peças da roupa de Carimbó. As demais crianças colocaram a boneca com a saia de Carimbó, porém com outras blusas, e o menino com a blusa florida, mas com outras bermudas e calças.

Segundo Giffoni (1973), existem diferentes e importantes valores para o trabalho com as danças folclóricas na escola, entre eles estão o valor físico, que é uma forma de exercício físico e completo, melhora as funções circulatórias, respiratórias, colabora para a agilidade e flexibilidade dos movimentos; e o valor moral, que incentiva e aperfeiçoa o domínio de si mesmo, a iniciativa, o entusiasmo e o senso de ordem.

Com isso encerramos as atividades dos aspectos motores com as crianças. Revelamos as formas que o Carimbó contribui para a obtenção da lateralidade, coordenação motora (grossa e fina) e agilidade.

No ínicio, a professora já havia relatado uma certa dificuldade de um dos meninos e nas primeiras atividades percebemos um certo desequilíbrio deste no ato de correr. Quando a atividade pedia corrida, ele sempre caía. E o fato das meninas estarem demonstrando um sentimento competitivo o deixava mais nervoso na hora de correr, fazendo-o perder o equilíbrio. Ele apresentou quedas durante a atividade inteira.

O desenvolvimento desses aspectos motores fundamentais é básico para o desenvolvimento motor e a educação motora das crianças. Para Wallon (1995), uma ampla variedade de experiências motoras fornece às crianças grande riqueza de informação, em que podem basear a percepção que têm de si próprias e do mundo que as rodeia.

Ao conversamos com a professora sobre o fato deles estarem trabalhando com o Carimbó, se houve algum comentário deles sobre o assunto dentro de sala, ela relatou que eles gostaram muito, e sempre chegavam em sala falando sobre as atividades realizadas: "eu rodei assim, fazendo alguns passos da dança ou cantando parte das músicas" (entrevista realizada em 17 de março de 2019); e nos momentos em que os alunos eram liberados para brincar, eles lembravam das brincadeiras e as reproduziam no parquinho. 
Para Wallon (2007), o desenvolvimento afetivo, cognitivo e motor têm ritmos diferentes conforme a relação orgânico-social se expressa em cada indivíduo, e as atividades precisam corresponder a esses ritmos. Assim, o ritmo deve ser respeitado e não avaliado. Portanto, ao final do estágio, teremos uma criança completa, com possibilidades e limitações próprias.

\section{Considerações finais}

Por meio da análise dos seis alunos da turma do maternal e dos questionários realizados com a professora, as observações do desenvolvimento das atividades e dos questionários, nos fez identificar as formas que o Carimbó, enquanto dança, contribui para o desenvolvimento da afetividade no aluno, como: caracterizar as habilidades do Carimbó que podem ser utilizadas para o desenvolvimento cognitivo, além de revelar as formas que o Carimbó contribui para coordenação motora.

Com isso, encontramos as formas que o Carimbó contribui para o desenvolvimento sensório-motor em alunos da Educação Infantil, especificamente da turma do Maternal, nas aulas de Educação Física em uma escola particular em Belém do Pará, por meio da dança, da construção de instrumentos, de atividades de quebra cabeça, corrida e de captura de objetos com ajuda de implementos ou não.

A imersão do Carimbó dentro das aulas de Educação Física nos permitiu, no aspecto afetivo, através das danças desenvolvidas nos bambolês; da reprodução dos movimentos da dança que os alunos realizaram; da dança ao som do Curimbó e das formas de manusear a saia para direcionar a bola no buraco, alcançar, o respeito ao próximo, a paciência, o controle das emoções, a espera, o aumento da interação com os colegas e o desenvolvimento do diálogo entre eles. No aspecto cognitivo, alcançamos a concentração, a memorização e o tato para criar estratégias que direcionassem a um melhor desenvolvimento na atividade. E no aspecto motor, com o deslocamento de um bambolê para o outro, através da corrida; com a construção dos instrumentos com garrafas pet e do quebra cabeça, alcançamos a coordenação motora grossa; com o colocar as pedrinhas na garrafa e as peças de roupa nos bonecos, desenvolvemos a coordenação motora fina. Assim, contribuindo para o desenvolvimento sensório-motor de cada um deles.

Nesse sentido, a pesquisa revela que o uso do Carimbó, ritmo característico da região norte, é elemento da cultura dessas crianças, para o desenvolvimento sensóriomotor, bem como os avanços das atividades, quando as crianças retornavam à sala de aula, falando sobre o ritmo e sobre as atividades desenvolvidas naquele dia. E isso 
estimulou a professora utilizar esse conteúdo para desenvolver suas aulas. Com isso, as crianças estavam cada vez mais próximas e familiarizadas com o Carimbó.

Durante a execução da pesquisa, encontramos alguns entraves em seu desenvolvimento, como por exemplo, que a nossa expectativa era de que os alunos estivessem sempre bem, psicologicamente. Porém, no decorrer das semanas, algumas crianças apresentavam impaciência e estresse durante as atividades. Esses alunos chegavam na escola apresentando esses comportamentos.

Com isso, no decorrer das aplicações dos instrumentos, já esperávamos que as crianças não teriam os mesmos comportamentos, como também não alcançariam os resultados juntos, pois cada um tem o seu tempo e sua individualidade quanto à aprendizagem e comportamento. Assim, presumimos que não seria fácil, pois teríamos que ter paciência e trabalhar com as crianças de formas diferentes, mesmo que as atividades fossem as mesmas. Nesse sentido, observamos que alguns compreendem mais rápidos que outros, e no questionário da professora estava detalhado o comportamento de cada aluno, suas particularidades, dificuldades e qualidades.

A pesquisa também sinalizou, que o conhecimento sobre o Carimbó não gerou estranhamento por parte das crianças, mesmo que o contato entre os alunos da pesquisa, seja mínimo sobre o assunto. Além disso, as atividades afetivas mostraram que os alunos conseguiram controlar suas emoções, adquiriram paciência e desenvolveram melhor a interação com os colegas.

As atividades cognitivas nos apresentaram um desenvolvimento da concentração e memorização; as atividades motoras um aprimoramento dos alunos; as atividades motoras, um domínio motor correspondente à faixa etária deles. Nessa perspectiva, a prática desse ritmo, Carimbó, é instrumento de desenvolvimento dentro das aulas como componente para desenvolver as competências propostas pela BNCC, podendo ser utilizado, como dança; como formas de atividades, em brincadeiras e jogos, por se tratar componente cultural característico da região paraense.

\section{Referências}

BASEl, Andréia Paula. A Educação Física na Educação Infantil: a importância do movimentar-se e suas contribuições no desenvolvimento da criança. Revista Iberoamericana de Educación, v. 47, n. 3, p. 1-12, 2008.

BRASIL. BNCC - Base Nacional Comum Curricular. Proposta Preliminar Primeira Versão Revista. Brasília, DF, 2016.

CAPARROZ, F. E. Entre a educação física na escola e a educação física da escola. 3. ed. 
CASCUDO, Luís da Câmara. Dicionário de folclore brasileiro. Brasília: Instituto Nacional do Livro, 1972.

COSTA, Tony Leão da. Carimbó e Brega: Indústria cultural e tradição na música popular do norte do Brasil. Revista Estudos Amazônicos, Belém v. VI, n. 1, p. 149 - 177, 2011.

FIGUEIREDO, Silvio Lima. BOGÉA, Eliana. Hibridismo cultural e atualização da cultura: o Carimbó do Brasil. Revista Resgate, Campinas, v. 23, n. 2, p. 81-92, 2015.

GABBAY, Marcello M. Representações sobre O Carimbó: Tradição X Modernidade. In: Anais do IX Congresso de Ciências da Comunicação na Região Norte - Intercom. Rio Branco: Intercom, 2010.

GIFFONI, Maria Amália Corrêa. Danças Folclóricas Brasileiras. 3. ed. São Paulo: Melhoramentos, 1973.

NEVES, Adriana Di Marco. A dança do Carimbó, 2013. Disponível em: <http://wikidanca.net/wiki/index.php/A_Dan\%C3\%A7a_do_Carimb\%C3\%B3>. Acesso em: 08 abr. 2018.

SALLES, Vicente, SALLES, Marena Isdebski. Carimbó: trabalho e lazer do caboclo. Revista Brasileira de Folclore, Rio de Janeiro, v. 9, n. 25, p. 257-282, set./ dez. 1969.

SOUZA JUNIOR, Marcílio et al. Coletivo de autores: a cultura corporal em questão. Rev. Bras. Ciênc. Esporte (Impr.) [online]. 2011, vol.33, n.2, pp.391-411. ISSN 0101-3289. https://doi.org/10.1590/S0101-32892011000200008.

SOUZA, Aparecida Ivonete Merenda. O professor PDE e os desafios da escola pública paranaense. v.2. Danças Folclóricas na Educação Física. Resgatando a Cultura Popular. 2011.

WALLON, Henri. A evolução psicológica da criança. São Paulo: Martins Fontes, 2007. WALLON, Henri. As origens do caráter da criança. São Paulo: Nova Alexandria, 1995. WALLON, Henri. Psicologia e Educação da Infância. Lisboa: Estampa, 1975. 


\section{ABSTRACT:}

This article highlights Carimbó as a symbol of traditional culture and the state of Pará identity, being an instrument to work according to Wallon theory on sensorymotor development. The matter discussed is about to know how Carimbó contributes to students sensory-motor development in Early Childhood Education (toddlers) in Physical Education classes. It's a qualitative case study research, that used a participatory observation instrument and an open interview with a teacher and six students. For data analysis, data triangulation was used. As a result, we understand that Carimbó made viable the students sensory-motor development. On this account it was possible to observe the development of the researched aspects.

KEYWORDS: Carimbó; Sensory-Motor Development; Physical Education.

\section{RESUMEN:}

Este artículo destaca, el Carimbó como símbolo de la cultura tradicional e identidad de Pará, un instrumento para trabajar la teoria de Wallon sobre el desarrollo sensoriomotor. Problematizó conocer la manera como el Carimbó contribuye al desarrollo sensoriomotor en alumnos de la Educación Infantil (primer ciclo) en las clases de Educación Física. La investigación cualitativa de Estudios de Caso, utilizó la observación participativa y entrevista abierta con una maestra y seis alumnos. Para el análisis de datos, se utilizó la Triangulación de Datos. Como resultados, entendemos que Carimbó posibilitó el desarrollo sensoriomotor de los alumnos, pues fue posible observar el desarrollo de los aspectos investigados.

PALABRAS-CLAVES: Carimbó; Desarrollo Sensoriomotor; Educación Física. 